\title{
Effects of gene polymorphisms on the risk of severe hyponatremia during DCF chemotherapy for patients with esophageal squamous cell carcinoma
}

\author{
YASUHIRO ARAKAWA ${ }^{1}$, YOSHIHIRO SHIRAI ${ }^{2}$, KAZUMI HAYASHI $^{1}$, YUJIRO TANAKA ${ }^{2}$, \\ AKIRA MATSUMOTO $^{2}$, KATSUNORI NISHIKAWA ${ }^{2}$ and SHINGO YANO ${ }^{1}$ \\ ${ }^{1}$ Division of Clinical Oncology and Hematology, Department of Internal Medicine; \\ ${ }^{2}$ Department of Surgery, The Jikei University School of Medicine, Tokyo 105-8471, Japan
}

Received February 19, 2018; Accepted July 25, 2018

DOI: $10.3892 / \mathrm{ol} .2018 .9236$

\begin{abstract}
Combination chemotherapy using docetaxel, cisplatin and 5-fluorouracil (DCF) is a promising treatment option for patients with advanced esophageal squamous cell carcinoma (ESCC), although its clinical application is limited by severe systemic toxicities. There are no validated markers for predicting the adverse effects caused by this regimen. This pharmacogenetic study enrolled 57 patients with chemotherapy-naive advanced ESCC between July 2012 and March 2016 (UMIN000008462). All patients received at least one course of DCF chemotherapy (docetaxel, $60 \mathrm{mg} / \mathrm{m}^{2}$ on day 1 ; cisplatin, $70 \mathrm{mg} / \mathrm{m}^{2}$ on day 1; 5-fluorouracil, $600 \mathrm{mg} / \mathrm{m}^{2}$ on days 1-5). The associations between four gene polymorphisms (ERCC1 rs11615, GSTP1 rs1695, TYMS rs151264360 and XPD rs13181) and the development of grade 3/4 adverse events during the first course of chemotherapy were prospectively investigated. The patients had a median age of 66 years (range, 45-77 years) and the majority were male (51 males vs. 6 females). The treatment settings were neoadjuvant (47 patients), adjuvant (1 patient) and salvage ( 9 patients), with dose intensities of $100 \%$ (51 patients) or $80 \%$ (6 patients). The severe adverse events were leukopenia $(70.2 \%)$, neutropenia $(86.0 \%)$, febrile neutropenia (36.8\%), acute kidney injury (29.1\%) and hyponatremia (43.9\%). Two polymorphisms were independently associated with the development of severe hyponatremia among patients carrying the minor allele (vs. patients with major homozygote genotype): TYMS 3'-UTR rs151264360 (odds ratio, 3.64; 95\% confidence interval, 1.11-11.9) and
\end{abstract}

Correspondence to: Dr Yasuhiro Arakawa, Division of Clinical Oncology and Hematology, Department of Internal Medicine, The Jikei University School of Medicine, 3-19-18 Nishishimbashi, Minato-Ku, Tokyo 105-8471, Japan

E-mail: arakawaz@gmail.com

Key words: esophageal cancer, squamous cell carcinoma, chemotherapy, severe toxicity, pharmacogenetic study
XPD Lys751Gln rs13181 (odds ratio, 10.1; 95\% confidence interval, 1.10-93.3). Therefore, the presence of the TYMS and XPD polymorphisms may aid in identifying patients with a high risk of developing severe hyponatremia during DCF chemotherapy.

\section{Introduction}

Esophageal cancer is a fatal disease that is characterized by frequent invasion of the surrounding tissues and early metastasis to the lymph nodes and distant organs. A number of patients are diagnosed at the advanced stages, which highlights the importance of effective systemic chemotherapy in the adjuvant or palliative settings. Combination chemotherapy using docetaxel, cisplatin and 5-fluorouracil (DCF) has shown promising efficacy in the adjuvant and salvage settings for patients with esophageal squamous cell carcinoma (ESCC) (1-3). However, its clinical application is limited by severe systemic toxicities, such as myelosuppression and acute kidney injury (AKI), and there are no established markers for predicting the development of severe adverse events during this intensive chemotherapy.

Many groups have suggested that polymorphisms in genes that are involved in drug transport, metabolism, and DNA repair may affect the patient's response to chemotherapy and its toxic effects. For example, the response to platinum/fluorouracil-based chemotherapy is associated with the nucleotide excision repair (NER) pathway genes [excision repair cross-complementing group 1 (ERCC1) and xeroderma pigmentosum group D (XPD)], the glutathione S-transferase (GST) family, and thymidylate synthase (TYMS) (4-6). In addition, ERCC and XPD play key roles in the repair of platinum-DNA adducts (7). Previous studies have demonstrated that the silent mutation at codon 118 (rs11615) affects the expression of ERCC1 mRNA and alters cellular sensitivity to platinum-containing chemotherapy $(8,9)$. Furthermore, the XPD Lys751Gln polymorphism (rs13181) is associated with suboptimal DNA repair capacity (10). These polymorphisms seem to have predictive value among patients receiving platinum-containing therapy for lung and gastrointestinal cancers $(9,11)$. 
The GST family of enzymes catalyze the conjunction of reduced glutathione to electrophilic molecules. Similar to other GSTs, GSTP1 is an important enzyme in the detoxification of electrophilic metabolites that are produced by various chemotherapeutic drugs (12). Furthermore, the Ile105Val polymorphism (rs1695) leads to an amino acid substitution in the catalytic site of GSTP1, which affects enzyme-substrate affinity (13). Several studies have also demonstrated that this polymorphism affects the outcomes among patients who received platinum-containing chemotherapy $(4,14,15)$.

TYMS is the only de novo source of thymidylate, which is necessary for DNA biosynthesis and is also the primary target of 5-fluorouracil. One meta-analysis has revealed that patients with colon cancer expressing high levels of TYMS seemed to have poor overall survival (16). In addition, a 6-bp polymorphism in the 3'-UTR region of the TYMS gene (rs151264360) causes mRNA instability and decreases TYMS expression $(17,18)$. Dotor et al (19) have demonstrated that the presence of a homozygous 3'-UTR 6-bp deletion in the tumor was associated with a survival benefit among patients receiving fluorouracil-based adjuvant chemotherapy for colorectal cancer.

Previous randomized trials have demonstrated that the addition of docetaxel to cisplatin/5-fluorouracil resulted in approximately double the rate of grade 3/4 leucopenia and febrile neutropenia (FN), although only one report has described a correlation between germline polymorphisms and adverse events during DCF chemotherapy (20-22). Thus, it would be useful to identify factors that predict chemotherapeutic response and toxicity, in order to select patients who are expected to experience the greatest treatment benefit. Therefore, this pharmacogenetic study aimed to identify polymorphisms with predictive value, which could facilitate tailored management of patients receiving intensive DCF chemotherapy.

\section{Patients and methods}

Patients. Sixty-one consecutive patients with pathologically confirmed, chemotherapy-naive, advanced ESCC were considered potentially eligible because they were about to undergo DCF chemotherapy in our department between July 2012 and March 2016. However, only 57 patients were enrolled after providing written informed consent to participate in this pharmacogenetic study. The baseline eligibility criteria for the DCF chemotherapy were an Eastern Cooperative Oncology Group performance status of $\leq 1$, a hemoglobin level of $\geq 8.0 \mathrm{~g} / \mathrm{dl}$, a white blood cell count of 3,000-12,000/ $\mu 1$, an absolute neutrophil count of $\geq 1,500 / \mu 1$, a platelet count of $\geq 80,000 / \mu 1$, a serum bilirubin level of $\leq 2 \mathrm{x}$ the upper limit of normal, serum transaminase levels of $\leq 3 \mathrm{x}$ the upper limit of normal, and a serum creatinine level of $\leq 1.3 \mathrm{mg} / \mathrm{dl}$. The study protocol was approved by the ethics review board of Jikei University (24-004) and was registered in the University Hospital Medical Information Network Clinical Trials Registry of Japan (UMIN000008462).

Chemotherapy. The patients received DCF chemotherapy as inpatient treatment (docetaxel: $60 \mathrm{mg} / \mathrm{m}^{2}$ on day 1, cisplatin: $70 \mathrm{mg} / \mathrm{m}^{2}$ on day 1 , and 5-fluorouracil: $600 \mathrm{mg} / \mathrm{m}^{2}$ on days 1-5) (2). The docetaxel was dissolved in $500 \mathrm{ml}$ of $5 \%$ glucose and administered via drip infusion for $1 \mathrm{~h}$. The cisplatin was dissolved in $500 \mathrm{ml}$ of normal saline and administered via drip infusion for $2 \mathrm{~h}$. The 5-fluorouracil was mixed with $1,000 \mathrm{ml}$ of normal saline and administered via continuous infusion for $24 \mathrm{~h}$. A total of 1,500 $\mathrm{ml}$ of normal saline was co-administered for $6 \mathrm{~h}$ before and after the cisplatin infusion, and magnesium sulfate $(10-20 \mathrm{mEq})$ was administered intravenously on day 1 . All patients received a routine emesis prophylaxis with aprepitant, palonosetron, and dexamethasone. Primary prophylactic use of granulocyte colony-stimulating factor (G-CSF) was not allowed, although therapeutic use of G-CSF was recommended when neutropenia was diagnosed. Prophylactic antibiotics were not used. All patients were hospitalized until bone marrow recovery.

Toxicity assessments. Blood testing and urinalysis were performed on day 8 the of chemotherapy regimen, and then complete blood count were performed at least every 3 days until bone marrow recovery. Complete blood count, blood chemistry, and urinalysis data during the first course of chemotherapy were collected by physicians who were blinded to the genotyping results. Adverse events were graded according to the Common Terminology Criteria for Adverse Events (v.4.0), and the highest grade during the first course was recorded. The presence of AKI was identified based on an increase in serum creatinine of $\geq 25 \%$ or $\geq 0.3 \mathrm{mg} / \mathrm{dl}$ from baseline.

Genotyping. All 57 patients provided whole-blood samples $(100 \mu \mathrm{l})$ that were subjected to genomic DNA extraction using the MagExtractor Genome kit (Toyobo Co., Ltd., Osaka, Japan). The regions containing the four polymorphisms (ERCC1 rs11615, GSTP1 rs1695, TYMS rs151264360, and XPD rs13181) were amplified using the FastStart High Fidelity PCR System (Roche Diagnostics GmbH, Mannheim, Germany) with the previously reported primer pairs (4; Table I). The thermal conditions for the PCR were $95^{\circ} \mathrm{C}$ for $2 \mathrm{~min}$, followed by 35 cycles of $95^{\circ} \mathrm{C}$ for $30 \mathrm{sec}, 57^{\circ} \mathrm{C}$ for $30 \mathrm{sec}, 72^{\circ} \mathrm{C}$ for $1 \mathrm{~min}$, and final extension at $72^{\circ} \mathrm{C}$ for $5 \mathrm{~min}$. All polymorphisms were subsequently analyzed via direct sequencing using the Big Dye Terminator v.3.1 cycle sequencing kit on the 3730 DNA Analyzer (Thermo Fisher Scientific, Inc., Waltham, MA, USA).

Statistical analysis. The observed genotype distributions and the distributions expected by the Hardy-Weinberg equilibrium were compared using Fisher's exact test. The patients' demographic and clinical characteristics were compared according to genotype using Fischer's exact test. All genotypes were subsequently dichotomized into two groups (major homozygote or minor allele carrier) and analyzed for associations with the development of grade $3 / 4$ adverse events. Multivariable analyses were performed using logistic regression with the following covariates: age ( $<65$ years or $\geq 65$ years), sex (male or female), treatment setting (neoadjuvant/adjuvant or salvage), and dose intensity (100 or $80 \%$ ). All statistical analyses were performed using EZR (Saitama Medical Center, Jichi Medical University, Saitama Japan), which is a graphical user interface for R software (The R Foundation for Statistical Computing, Vienna, Austria) that incorporates frequently used biostatistics functions (23). All statistical tests were two-sided and $\mathrm{P}<0.05$ 
Table I. Primer sequences for the selected polymorphisms.

\begin{tabular}{lcl}
\hline & $\begin{array}{c}\text { Polymorphism } \\
\text { Gene }\end{array}$ & \\
& ID & \multicolumn{1}{c}{ Primers } \\
ERCC1 & \multirow{2}{*}{ rs11615 } & F:5'-GCAGAGCTCACCTGAGG \\
& & AAC-3' \\
& & R: 5'-GAGGTGCAAGAAGAGG \\
& & TGGA-3' \\
FSTP1 & \multirow{2}{*}{ rs1695 } & GACCCCAGGGCTCTATGG \\
& & R: 5'-TGAGGGCACAAGAAGC \\
& & CCCT-3' \\
& & F: 5'-CAAATCTGAGGGAGCTG \\
TYMS & rs151264360 AGT-3' \\
& & R: 5'-CAGATAAGTGGCAGTAC \\
& & AGA-3' \\
& & F: 5'-CCTCTCCCTTCCTCTG \\
XPD & rs13181 & TTC-3' \\
& & R: 5'-CAGGTGAGGGGGACA \\
& & TCT-3' \\
& &
\end{tabular}

F, forward; R, reverse primer.

was considered to indicate a statistically significant difference. Because of the present study's exploratory nature, adjustment for multiple testing was not performed (24).

\section{Results}

Patient characteristics. The 57 patients' characteristics are shown in Table II. The median age was 66 years (range: 45-77 years), most patients were male (51 men vs. 6 women), and most patients $(82.5 \%)$ were treated in the neoadjuvant setting. Six patients $(10.5 \%)$ who were $>70$ years old had a dose reduction by one level to $80 \%$ for each drug.

Polymorphism distributions. The genotyping results for the four polymorphisms were available for all patients (Table III). All analyzed polymorphisms had distributions that were in agreement with the Hardy-Weinberg equilibrium (25), and did not differ from those in the 1000 Genomes Project Japanese in Tokyo, Japan (JPT) population (26), http://phase3browser.1000genomes.org/index.html). No significant associations were observed between the genotypes and the patients' characteristics (Table IV).

Adverse events and the development of AKI. Table V shows the incidences of the grade 3/4 adverse events and AKI during the first course of DCF chemotherapy. Despite the high incidences of leukopenia, neutropenia, and FN, no chemotherapy-related mortality occurred. The incidence of severe (grade 3/4) anemia was only $3.5 \%$. Based on our stringent criteria, the incidence of AKI was $29.8 \%$. The incidence of grade $3 / 4$ hyponatremia was $43.9 \%$. The incidence of severe diarrhea was relatively low $(7 \%)$. Grade 3/4 peripheral neuropathy was not observed in the present study. The risk of neutropenic complications is
Table II. Patient characteristics.

Characteristic

No. patients $(n=57)$

$\begin{array}{lc}\text { Age, years } & \\ \text { Median } & 66 \\ \text { Range } & 45-77 \\ \text { Sex, n (\%) } & \\ \text { Male } & 51(89.5) \\ \text { Female } & 6(10.5) \\ \text { Treatment, n (\%) } & \\ \text { Neoadjuvant } & 47(82.5) \\ \text { Adjuvant } & 1(1.8) \\ \text { Salvage } & 9(15.8) \\ \text { Dose intensity, n }(\%) & \\ 100 \% & 51(89.5) \\ 80 \% & 6(10.5)\end{array}$

Table III. Distribution of genotypes.

\begin{tabular}{|c|c|c|c|}
\hline Genotype & $\mathrm{n}(\%)$ & HWE (P) & JPT (\%) \\
\hline \multicolumn{4}{|l|}{ ERCC1 rs11615 } \\
\hline $\mathrm{C}>\mathrm{T}$ (Asn118Asn) & & 0.74 & \\
\hline $\mathrm{T} / \mathrm{T}$ & $5(8.8)$ & & $10(9.6)$ \\
\hline $\mathrm{T} / \mathrm{C}$ & $21(36.8)$ & & $41(39.4)$ \\
\hline $\mathrm{C} / \mathrm{C}$ & $31(54.4)$ & & $53(51.0)$ \\
\hline \multicolumn{4}{|l|}{ GSTP1 rs 1695} \\
\hline A > G (Ile105Val) & & 0.64 & \\
\hline $\mathrm{A} / \mathrm{A}$ & $40(70.2)$ & & $85(81.7)$ \\
\hline $\mathrm{A} / \mathrm{G}$ & $15(26.3)$ & & $17(16.3)$ \\
\hline $\mathrm{G} / \mathrm{G}$ & $2(3.5)$ & & $2(1.9)$ \\
\hline \multicolumn{4}{|l|}{ TYMS rs 151264360} \\
\hline 3'-UTR 6 bp ins/del & & 0.24 & \\
\hline $6 \mathrm{bp} / 6 \mathrm{bp}$ & $4(7.0)$ & & $14(13.5)$ \\
\hline $6 \mathrm{bp} / 0 \mathrm{bp}$ & $30(52.6)$ & & $44(42.3)$ \\
\hline $0 \mathrm{bp} / 0 \mathrm{bp}$ & $23(40.4)$ & & $46(44.1)$ \\
\hline \multicolumn{4}{|l|}{ XPD rs13181 } \\
\hline $\mathrm{T}>\mathrm{G}$ (Lys751Gln) & & 1.00 & \\
\hline $\mathrm{T} / \mathrm{T}$ & $50(87.7)$ & & $91(87.5)$ \\
\hline $\mathrm{T} / \mathrm{G}$ & $7(12.3)$ & & $12(11.5)$ \\
\hline $\mathrm{G} / \mathrm{G}$ & $0(0)$ & & $1(1.0)$ \\
\hline
\end{tabular}

HWE, Hardy-Weinberg equilibrium; JPT, 1000 Genomes Project, Japanese in Tokyo, Japan; ERCC1, excision repair cross-complementing group 1; GSTP1, glutathione S-transferase P1; TYMS, thymidylate synthase; UTR, untranslated region; XPD, xeroderma pigmentosum group D.

correlated with both the severity and duration of neutropenia, with FN being the most serious consequence of neutropenia. Therefore, we selected FN, AKI, and hyponatremia for further analysis based on their clinical relevance and high frequency. 
Table IV. Genotypes and patient characteristics.

\begin{tabular}{|c|c|c|c|c|c|c|c|c|c|}
\hline \multirow[b]{2}{*}{ Genotype } & \multicolumn{3}{|c|}{ Age in years, $n$} & \multicolumn{3}{|c|}{ Sex, $n$} & \multicolumn{3}{|c|}{ Treatment setting, $\mathrm{n}$} \\
\hline & $<65$ & $\geq 65$ & P-value & M & $\mathrm{F}$ & P-value & Adj & Salv & P-value \\
\hline ERCC1 & & & 0.57 & & & 1 & & & 0.87 \\
\hline $\mathrm{T} / \mathrm{T}$ & 2 & 3 & & 5 & 0 & & 5 & 0 & \\
\hline $\mathrm{T} / \mathrm{C}$ & 7 & 14 & & 19 & 2 & & 17 & 4 & \\
\hline $\mathrm{C} / \mathrm{C}$ & 15 & 16 & & 27 & 4 & & 26 & 5 & \\
\hline GSTP1 & & & 0.53 & & & 1 & & & 0.46 \\
\hline $\mathrm{A} / \mathrm{A}$ & 15 & 25 & & 35 & 5 & & 35 & 5 & \\
\hline $\mathrm{A} / \mathrm{G}$ & 8 & 7 & & 14 & 1 & & 11 & 4 & \\
\hline $\mathrm{G} / \mathrm{G}$ & 1 & 1 & & 2 & 0 & & 2 & 0 & \\
\hline TYMS & & & 0.35 & & & 0.50 & & & 1 \\
\hline $6 \mathrm{bp} / 6 \mathrm{bp}$ & 3 & 1 & & 4 & 0 & & 4 & 0 & \\
\hline $6 \mathrm{bp} / 0 \mathrm{bp}$ & 13 & 17 & & 28 & 2 & & 25 & 5 & \\
\hline $0 \mathrm{bp} / 0 \mathrm{bp}$ & 8 & 15 & & 19 & 4 & & 19 & 4 & \\
\hline XPD & & & 1 & & & 1 & & & 0.58 \\
\hline $\mathrm{T} / \mathrm{T}$ & 21 & 29 & & 44 & 6 & & 41 & 9 & \\
\hline $\mathrm{T} / \mathrm{G}$ & 3 & 4 & & 7 & 0 & & 7 & 0 & \\
\hline $\mathrm{G} / \mathrm{G}$ & 0 & 0 & & 0 & 0 & & 0 & 0 & \\
\hline
\end{tabular}

M, male; F, female; Adj, adjuvant; Salv, salvage; ERCC1, excision repair cross-complementing group 1; GSTP1, glutathione S-transferase P1; TYMS, thymidylate synthase; UTR, untranslated region; XPD, xeroderma pigmentosum group D.

Table V. Incidence of grade 3/4 adverse events and acute kidney injury.

Adverse event Total patients $(n=57)$

$\begin{array}{lc}\text { Hematological, n }(\%) & \\ \text { Leukopenia (grade 3/4) } & 40(70.2) \\ \text { Neutropenia (grade 3/4) } & 49(86.0) \\ \text { Febrile neutropenia } & 21(36.8) \\ \text { Anemia (grade 3/4) } & 2(3.5) \\ \text { Non-hematological, n (\%) } & \\ \text { Acute kidney injury } & 17(29.8) \\ \text { Hyponatremia (grade 3/4) } & 25(43.9) \\ \text { Diarrhea (grade 3/4) } & 4(7.0)\end{array}$

Leukopenia (grade 3/4), white blood cell count of $<2,000 / \mu 1$; neutropenia (grade $3 / 4$ ), absolute neutrophil count of $<1,000 / \mu 1$; anemia (grade 3/4), hemoglobin level of $<8.0 \mathrm{~g} / \mathrm{dl}$; hyponatremia (grade $3 / 4$ ), serum sodium concentration of $\leq 130 \mathrm{mEq} / \mathrm{l}$.

Association between genotypes and severe adverse events. Univariable analysis revealed that grade 3/4 hyponatremia was significantly more common among patients with the TYMS $6 \mathrm{bp} / 6 \mathrm{bp}$ or $6 \mathrm{bp} / 0 \mathrm{bp}$ genotypes (minor allele carriers) than among patients with the $0 \mathrm{bp} / 0 \mathrm{bp}$ genotype (major homozygote genotype) (Fisher's exact test, $\mathrm{P}=0.033$, Table VI). Grade 3/4 hyponatremia was also significantly more common among patients with the XPD 751Gln minor allele $(\mathrm{G} / \mathrm{G}$ or $\mathrm{T} / \mathrm{G}$; minor allele carriers) than among patients with the major homozygote genotype (Fisher's exact test, $\mathrm{P}=0.036$, Table VI). None of the analyzed polymorphisms were associated with the development of FN or AKI. Multivariable logistic regression analysis that was adjusted for age, sex, treatment setting, and dose intensity revealed that, relative to patients with the major homozygote genotypes, grade 3/4 hyponatremia was independently associated with the TYMS 6-bp insertion allele (adjusted odds ratio: 3.64, 95\% confidence interval: 1.11-11.9) and the XPD 751Gln minor allele (adjusted odds ratio: 10.1, 95\% confidence interval: 1.10-93.3) (Table VII).

\section{Discussion}

The present study revealed that TYMS and XPD polymorphisms were associated with the development of severe hyponatremia during DCF chemotherapy, as patients with the minor alleles for TYMS or XPD gene were more likely to develop grade 3/4 hyponatremia than patients with the major homozygous genotypes. The incidence of grade $3 / 4$ hyponatremia was somewhat elevated in the present study, although previous reports have also described a high risk of severe hyponatremia among patients with esophageal cancer who received DCF chemotherapy $(3,27-29)$. This elevated risk of severe hyponatremia may be related to racial/ethnic differences, or it is possible that hyponatremia events were not fully captured during other comparable studies. The advantage of the present study is that complete data for all four polymorphisms were available for all patients, and reliable toxicity data were prospectively collected in the inpatient setting. The rate of AKI (29.8\%) was likely related to our use 
Table VI. Associations between the genotypes with febrile neutropenia, AKI and hyponatremia.

\begin{tabular}{|c|c|c|c|c|c|c|c|c|c|}
\hline \multirow[b]{2}{*}{ Genotype } & \multicolumn{3}{|c|}{$\mathrm{FN}, \mathrm{n}$} & \multicolumn{3}{|c|}{ AKI, $n$} & \multicolumn{3}{|c|}{ Hyponatremia, n } \\
\hline & + & - & P-value & + & - & P-value & + & - & P-value \\
\hline ERCC1 & & & 1.0 & & & 0.77 & & & 1.0 \\
\hline $\mathrm{C} / \mathrm{C}$ & 11 & 20 & & 10 & 21 & & 14 & 17 & \\
\hline $\mathrm{T} / \mathrm{T}, \mathrm{T} / \mathrm{C}$ & 10 & 16 & & 7 & 19 & & 11 & 15 & \\
\hline GSTP1 & & & 0.073 & & & 1.0 & & & 0.40 \\
\hline $\mathrm{A} / \mathrm{A}$ & 18 & 22 & & 12 & 28 & & 16 & 24 & \\
\hline $\mathrm{G} / \mathrm{G}, \mathrm{A} / \mathrm{G}$ & 3 & 14 & & 5 & 12 & & 9 & 8 & \\
\hline TYMS & & & 0.26 & & & 0.14 & & & $0.033^{\mathrm{a}}$ \\
\hline $0 \mathrm{bp} / 0 \mathrm{bp}$ & 6 & 17 & & 4 & 19 & & 6 & 17 & \\
\hline $6 \mathrm{bp} / 6 \mathrm{bp}, 6 \mathrm{bp} / 0 \mathrm{bp}$ & 15 & 19 & & 13 & 21 & & 19 & 15 & \\
\hline XPD & & & 0.70 & & & 0.42 & & & $0.036^{\mathrm{a}}$ \\
\hline $\mathrm{T} / \mathrm{T}$ & 18 & 32 & & 14 & 36 & & 19 & 31 & \\
\hline $\mathrm{G} / \mathrm{G}, \mathrm{T} / \mathrm{G}$ & 3 & 4 & & 3 & 4 & & 6 & 1 & \\
\hline
\end{tabular}

${ }^{a} \mathrm{P}<0.05$. FN, febrile neutropenia; AKI, acute kidney injury; ERCC1, excision repair cross-complementing group 1; GSTP1, glutathione S-transferase P1; TYMS, thymidylate synthase; XPD, xeroderma pigmentosum group D.

Table VII. Associations between the genotypes and hyponatremia (multivariable analysis).

\begin{tabular}{lcc}
\hline Genotype & Adjusted OR (95\% CI) & P-value \\
\hline TYMS & & 0.033 \\
$0 \mathrm{bp} / 0 \mathrm{bp}$ & Ref & \\
$6 \mathrm{bp} / 6 \mathrm{bp}, 6 \mathrm{bp} / 0 \mathrm{bp}$ & $3.64(1.11-11.9)$ & \\
XPD & & 0.041 \\
T/T & Ref & \\
G/G, T/G & $10.1(1.10-93.3)$ & \\
\hline
\end{tabular}

The OR and 95\% CI were adjusted for the incidence of hyponatremia. OR, odds ratio; CI, confidence interval; TYMS, thymidylate synthase; $\mathrm{XPD}$, xeroderma pigmentosum group $\mathrm{D}$; ref, reference.

of stringent criteria, and the relatively high incidence of $\mathrm{FN}$ (36.8\%) may be related to the fact that we did not perform primary prophylaxis using G-CSF or antibiotics.

The present study focused on the adverse events that occurred during the first course of chemotherapy, as 15 patients received only one course of full-dose chemotherapy (6 patients changed to chemoradiotherapy, 5 patients experienced disease progression, 2 patients changed hospitals, 1 patient developed grade 4 hyponatremia, and 1 patient was found to have another cancer). In addition, 9 patients who developed severe adverse events during the first course received a reduced dose of chemotherapy in the following courses. Gene polymorphisms are thought to be more closely associated with adverse events, rather than anticancer effects of chemotherapy, because loss of heterozygosity and allelic imbalance are frequently observed in cancer tissues. For example, the TYMS gene is on the short arm of chromosome 18, and allelic loss or amplification of this region has frequently described in many cancers, including $\operatorname{ESCC}(17,30,31)$.

Many studies have demonstrated that the ERCC1 rs11615 polymorphism is associated with the efficacy/toxicity of platinum-containing chemotherapy. Although there remains controversy regarding this topic, the rs $11615 \mathrm{C}$ allele is generally associated with a good response and favorable outcomes among patients with various cancers who are treated using platinum-based chemotherapy $(9,11)$. Other studies have revealed an association between the $\mathrm{C}$ allele and platinum-induced toxicity (32-34). We failed to detect an association between the ERCC1 rs11615 polymorphism and severe toxicity, which may be related to the reduced effect of platinum-related toxicity in the triplet regimen.

We also failed to detect an association between the GSTP1 ra1695 polymorphism and severe adverse events. In this context, the GSTP1 rs1695 polymorphism is thought to be associated with platinum- and taxane-induced neuropathy, and the A/A genotype increases the risk of severe neuropathy (35-38). However, none of our patients developed severe neuropathy. Other studies have revealed associations between the GSTP1 rs1695 polymorphism and other toxicities $(39,40)$, although the phenotypic effect of the GSTP1 polymorphism on chemotherapy-related toxicity has been inconsistent. In terms of esophageal cancer susceptibility, a meta-analysis of 21 case-control studies has indicated that the GSTP1 Ile105Val polymorphism was associated with the risk of ESCC (41), although our observed genotype distribution for GSTP1 did not differ from that of the JPT population (Table III).

To the best of our knowledge, no studies have explored the associations of gene polymorphisms with chemotherapy-induced hyponatremia, and the only report regarding gene polymorphisms and adverse events during DCF chemotherapy did not refer to the development of hyponatremia (22). Hyponatremia after cisplatin-containing chemotherapy may 
be related to renal salt wasting caused by tubular injury, hormonal abnormalities that cause inappropriate secretion of antidiuretic hormone, or insufficient sodium intake. It is not likely that hyponatremia was associated with the cancer itself, because no patients exhibited grade 3 or greater hyponatremia before chemotherapy. However, it remains unclear how the TYMS and XPD polymorphisms might biologically affect the development of hyponatremia during chemotherapy.

Although TYMS is the primary target of fluorouracil, fluorouracil itself has not been shown to cause renal damage or electrolyte imbalance (42). Nevertheless, a 6-bp insertion polymorphism in the TYMS 3'-UTR region was associated with high TYMS expression $(17,18,43)$. Another polymorphism has been described in the TYMS 5'-UTR region containing triple repeats $(3 \mathrm{R})$ or double repeats $(2 \mathrm{R})$ of a 28 -bp sequence, and the $2 \mathrm{R}$ allele is associated with low TYMS expression $(17,43)$. In addition, the TYMS 3'-UTR and the 5'-UTR polymorphisms were in linkage disequilibrium, and the $2 \mathrm{R} / 6 \mathrm{bp}$ haplotype was associated with a risk of severe side effects during fluorouracil-based chemotherapy (44). However, we did not evaluate the TYMS 5'-UTR polymorphism and cannot fully estimate the association between TYMS expression and the development of hyponatremia.

Cisplatin predominantly accumulates within the kidneys proximal tubular cells, which causes tubular cell injury and leads to AKI. Recent studies have demonstrated that DNA damage and the subsequent DNA damage response play a critical pathogenic role in cisplatin-induced AKI (45), with the related DNA damage (platinum-DNA adduct) being recognized and repaired by the NER system. As XPD is a key enzyme in the NER pathway, changes in its activity may alter cellular sensitivity to cisplatin (7). Furthermore, the XPD Lys751Gly polymorphism is related to reduced DNA repair capacity, and patients with this polymorphism have a good response to platinum-based chemotherapy for many types of cancers $(7,10,46)$. However, the components of the NER pathway have rarely been investigated in relation to the development of adverse effects in cisplatin-based chemotherapy. Polymorphisms in DNA repair gene have also been associated with esophageal cancer risk and some studies have demonstrated that the XPD $751 \mathrm{Gln} / \mathrm{Gln}$ genotype was associated with the risk of ESCC (vs. the XPD 751 Lys/Lys genotype (47,48), although the XPD $751 \mathrm{Gln} / \mathrm{Gln}$ genotype was not observed in our study (Table III).

In conclusion, the present study demonstrated that grade 3/4 hyponatremia was common during DCF chemotherapy and associated with TYMS and XPD polymorphisms. However, the mechanisms underlying these relationships remain unclear, and additional pharmacokinetic analysis and in vitro testing are needed. Moreover, independent cohorts are needed to confirm whether these gene polymorphisms can predict chemotherapy-induced hyponatremia, given the present study's single-center design. The present study also only evaluated patients with ESCC, which may limit the generalizability of the results. Nevertheless, our findings provide insight regarding the prediction of severe adverse events during cisplatin-containing intensive combination chemotherapy.

\section{Acknowledgements}

Not applicable.

\section{Funding}

No funding was received.

\section{Availability of data and materials}

All data generated or analyzed during the present study are included in this published article.

\section{Authors' contributions}

YA and YS are responsible for the study concept and design. YA, KH, UY, AM and KN acquired the data. YA, YS, KH, YT, AM, KN, SY analyzed and interpreted the data. YA prepared and edited the manuscript. YA, YS, KH, YT, AM, KN and SY reviewed the manuscript.

\section{Ethics approval and consent to participate}

All patients provided written informed consent. The study protocol was approved by the Institutional Ethics Review Board of The Jikei University School of Medicine (Tokyo, Japan), and was registered with the University Hospital Medical Information Network Clinical Trials Registry of Japan (no. UMIN000008462).

\section{Patient consent for publication}

Not applicable.

\section{Competing interests}

The authors declare that they have no competing interests.

\section{References}

1. Yokota T, Hatooka S, Ura T, Abe T, Takahari D, Shitara K, Nomura M, Kondo C, Mizota A, Yatabe Y, et al: Docetaxel plus 5-fluorouracil and cisplatin (DCF) induction chemotherapy for locally advanced borderline-resectable T4 esophageal cancer. Anticancer Res 31: 3535-3541, 2011.

2. Tamura S, Imano M, Takiuchi H, Kobayashi K, Imamoto H, Miki H, Goto Y, Aoki T, Peng YF, Tsujinaka T, et al: Phase II study of docetaxel, cisplatin and 5-fluorouracil (DCF) for metastatic esophageal cancer (OGSG 0403). Anticancer Res 32: 1403-1408, 2012.

3. Sugawara M, Katada C, Katada N, Takahashi K, Higuchi K, Komori S, Moriya H, Ishiyama H, Yamashita K, Sakuramoto S, et al: Retrospective evaluation of adverse events of neoadjuvant or induction chemotherapy with docetaxel, cisplatin, and 5-fluorouracil in esophageal squamous cell carcinoma. Esophagus 10: 65-69, 2013.

4. Stoehlmacher J, Park DJ, Zhang W, Yang D, Groshen S, Zahedy S and Lenz HJ: A multivariate analysis of genomic polymorphisms: Prediction of clinical outcome to 5-FU/oxaliplatin combination chemotherapy in refractory colorectal cancer. Br J Cancer 91: 344-354, 2004

5. Paré L, Marcuello E, Altés A, del Río E, Sedano L, Salazar J, Cortés A, Barnadas A and Baiget M: Pharmacogenetic prediction of clinical outcome in advanced colorectal cancer patients receiving oxaliplatin/5-fluorouracil as first-line chemotherapy. Br J Cancer 99: 1050-1055, 2008.

6. Deenen MJ, Cats A, Beijnen JH and Schellens JH: Part 4: Pharmacogenetic variability in anticancer pharmacodynamic drug effects. Oncologist 16: 1006-1020, 2011.

7. Bowden NA: Nucleotide excision repair: Why is it not used to predict response to platinum-based chemotherapy? Cancer Lett 346: 163-171, 2014. 
8. Yu JJ, Mu C, Lee KB, Okamoto A, Reed EL, Bostick-Bruton F, Mitchell KC and Reed E: A nucleotide polymorphism in ERCC1 in human ovarian cancer cell lines and tumor tissues. Mutat Res 382: 13-20, 1997.

9. Yang Y and Xian L: The association between the ERCC1/2 polymorphisms and the clinical outcomes of the platinum-based chemotherapy in non-small cell lung cancer (NSCLC): A systematic review and meta-analysis. Tumor Biol 35: 2905-2921, 2014.

10. Zhang G, Guan Y, Zhao Y, van der Straaten T, Xiao S, Xue P, Zhu G, Liu Q, Cai Y, Jin C, et al: ERCC2/XPD Lys751Gln alter DNA repair efficiency of platinum-induced DNA damage through P53 pathway. Chem Biol Interact 263: 55-65, 2017.

11. Yin M, Yan J, Martinez-Balibrea E, Graziano F, Lenz HJ, Kim HJ, Robert J, Im SA, Wang WS, Etienne-Grimaldi MC and Wei Q: ERCC1 and ERCC2 polymorphisms predict clinical outcomes of oxaliplatin-based chemotherapies in gastric and colorectal cancer: A systemic review and meta-analysis. Clin Cancer Res 17: 1632-1640, 2011.

12. Tew KD: Redox in redux: Emergent roles for glutathione S-transferase P (GSTP) in regulation of cell signaling and S-glutathionylation. Biochem Pharmacol 73: 1257-1269, 2007.

13. Moyer AM, Salavaggione OE, Wu TY, Moon I, Eckloff BW, Hildebrandt MA, Schaid DJ, Wieben ED and Weinshilboum RM: Glutathione s-transferase p1: Gene sequence variation and functional genomic studies. Cancer Res 68: 4791-4801, 2008.

14. Stoehlmacher J, Park DJ, Zhang W, Groshen S, Tsao-wei DD, $\mathrm{Yu} \mathrm{MC}$ and Lenz $\mathrm{HJ}$ : Association between glutathione S-transferase P1, T1, and M1 genetic polymorphism and survival of patients with metastatic colorectal cancer. J Natl Cancer Inst 94: 936-942, 2002

15. Wang Z, Chen JQ, Liu JL, Qin XG and Huang Y: Polymorphisms in ERCC1, GSTs, TS and MTHFR predict clinical outcomes of gastric cancer patients treated with platinum/5-Fu-based chemotherapy: A systematic review. BMC Gastroenterol 12: 137, 2012.

16. Popat S, Matakidou A and Houlston RS: Thymidylate synthase expression and prognosis in colorectal cancer: A systematic review and meta-analysis. J Clin Oncol 22: 529-536, 2004.

17. Lurje G, Manegold PC, Ning Y, Pohl A, Zhang W and Lenz HJ: Thymidylate synthase gene variations: Predictive and prognostic markers. Mol Cancer Ther 8: 1000-1007, 2009.

18. Mandola MV, Stoehlmacher J, Zhang W, Groshen S, Yu MC, Iqbal S, Lenz HJ and Ladner RD: A 6 bp polymorphism in the thymidylate synthase gene causes message instability and is associated with decreased intratumoral TS mRNA levels. Pharmacogenetics 14: 319-327, 2004.

19. Dotor E, Cuatrecases M, Martínez-Iniesta M, Navarro M, Vilardell F, Guinó E, Pareja L, Figueras A, Molleví DG, Serrano T, et al: Tumor thymidylate synthase 1494del6 genotype as a prognostic factor in colorectal cancer patients receiving fluorouracil-based adjuvant treatment. J Clin Oncol 24: 1603-1611, 2006

20. Van Cutsem E, Moiseyenko VM, Tjulandin S, Majlis A, Constenla M, Boni C, Rodrigues A, Fodor M, Chao Y, Voznyi E, et al: Phase III study of docetaxel and cisplatin plus fluorouracil compared with cisplatin and fluorouracil as first-line therapy for advanced gastric cancer: A report of the V325 study group. J Clin Oncol 24: 4991-4997, 2006.

21. Posner MR, Hershock DM, Blajman CR, Mickiewicz E, Winquist E, Gorbounova V, Tjulandin S, Shin DM, Cullen K, Ervin TJ, et al: Cisplatin and fluorouracil alone or with docetaxe in head and neck cancer. N Engl J Med 357: 1705-1715, 2007.

22. Melchardt T, Hufnagl C, Magnes T, Weiss L, Hutarew G, Neureiter D, Schlattau A, Moser G, Gaggl A, Tränkenschuh W, et al: CYP39A1 polymorphism is associated with toxicity during intensive induction chemotherapy in patients with advanced head and neck cancer. BMC Cancer 15 $725,2015$.

23. Kanda Y: Investigation of the freely available easy-to-use software 'EZR' for medical statistics. Bone Marrow Transplant 48 452-458, 2013

24. Bender R and Lange S: Adjusting for multiple testing-when and how? J Clin Epidemiol 54: 343-349, 2001

25. Graffelman J: Exploring diallelic genetic markers: The HardyWeinberg package. J Stat Softw 64: 1-23, 2015.

26. 1000 Genomes Project Consortium, Auton A, Brooks LD, Durbin RM, Garrison EP, Kang HM, Korbel JO, Marchini JL, McCarthy S, McVean GA and Abecasis GR: A global reference for human genetic variation. Nature 526: 68-74, 2015.
27. Matsumoto A, Nishikawa K, Yuda M, Tanaka Y, Tanishima Y, Arakawa Y, Ishibashi Y, Sakuyama T, Omura N, Mitsumori N, et al: Early response of esophageal cancer to neoadjuvant chemotherapy with docetaxel-cisplatin-5-Fluorouracil represents sensitivity: A phase II study. Anticancer Res 36: 1937-1942, 2016

28. Noronha V, Joshi A, Jandyal S, Jambhekar N and Prabhash K: High pathologic complete remission rate from induction docetaxel, platinum and fluorouracil (DCF) combination chemotherapy for locally advanced esophageal and junctional cancer. Med Oncol 31: 188, 2014

29. Arakawa Y, Tamura M, Sakuyama T, Aiba K, Eto S, Yuda M, Tanaka Y, Matsumoto A and Nishikawa K: Early measurement of urinary $\mathrm{N}$-acetyl- $\beta$-glucosaminidase helps predict severe hyponatremia associated with cisplatin-containing chemotherapy. J Infect Chemother 21: 502-506, 2015.

30. Hu N, Roth MJ, Polymeropolous M, Tang ZZ, Emmert-Buck MR, Wang QH, Goldstein AM, Feng SS, Dawsey SM, Ding T, et al: Identification of novel regions of allelic loss from a genomewide scan of esophageal squamous-cell carcinoma in a high-risk Chinese population. Genes Chromosomes Cancer 27: 217-228, 2000.

31. Nakakuki K, Imoto I, Pimkhaokham A, Fukuda Y, Shimada Y, Imamura M, Amagasa $\mathrm{T}$ and Inazawa J: Novel targets for the 18 p11.3 amplification frequently observed in esophageal squamous cell carcinomas. Carcinogenesis 23: 19-24, 2002.

32. Cortejoso L, García MI, García-Alfonso P, González-Haba E, Escolar F, Sanjurjo M and López-Fernández LA: Differential toxicity biomarkers for irinotecan- and oxaliplatin-containing chemotherapy in colorectal cancer. Cancer Chemother Pharmacol 71: 1463-1472, 2013.

33. Deenen MJ, Meulendijks D, Boot H, Legdeur MC, Beijnen JH, Schellens JH and Cats A: Phase $1 \mathrm{a} / 1 \mathrm{~b}$ and pharmacogenetic study of docetaxel, oxaliplatin and capecitabine in patients with advanced cancer of the stomach or the gastroesophageal junction. Cancer Chemother Pharmacol 76: 1285-1295, 2015.

34. Lambrechts S, Lambrechts D, Despierre E, Van Nieuwenhuysen E, Smeets D, Debruyne PR, Renard V, Vroman P, Luyten D, Neven P, et al: Genetic variability in drug transport, metabolism or DNA repair affecting toxicity of chemotherapy in ovarian cancer. BMC Pharmacol Toxicol 16: 2, 2015.

35. Lecomte T, Landi B, Beaune P, Laurent-Puig P and Loriot MA: Glutathione S-transferase P1 polymorphism (Ile105Val) predicts cumulative neuropathy in patients receiving oxaliplatin-based chemotherapy. Clin Cancer Res 12: 3050-3056, 2006.

36. McLeod HL, Sargent DJ, Marsh S, Green EM, King CR Fuchs CS, Ramanathan RK, Williamson SK, Findlay BP, Thibodeau SN, et al: Pharmacogenetic predictors of adverse events and response to chemotherapy in metastatic colorectal cancer: results from North American gastrointestinal intergroup trial N9741. J Clin Oncol 28: 3227-3233, 2010.

37. Li QF, Yao RY, Liu KW, Lv HY, Jiang T and Liang J: Genetic polymorphism of GSTP1: Prediction of clinical outcome to oxaliplatin/5-FU-based chemotherapy in advanced gastric cancer. J Korean Med Sci 25: 846-852, 2010.

38. Mir O, Alexandre J, Tran A, Durand JP, Pons G, Treluyer JM and Goldwasser F: Relationship between GSTP1 Ile(105)Val polymorphism and docetaxel-induced peripheral neuropathy: Clinical evidence of a role of oxidative stress in taxane toxicity. Ann Oncol 20: 736-740, 2009.

39. Liu YP, Ling Y, Qi QF, Zhang YP, Zhang CS, Zhu CT, Wang MH and Pan YD: Genetic polymorphisms of ERCC1-118, XRCC1-399 and GSTP1-105 are associated with the clinical outcome of gastric cancer patients receiving oxaliplatin-based adjuvant chemotherapy. Mol Med Rep 7: 1904-1911, 2013.

40. Goekkurt E, Al-Batran SE, Hartmann JT, Mogck U, Schuch G, Kramer M, Jaeger E, Bokemeyer C, Ehninger G and Stoehlmacher J: Pharmacogenetic analyses of a phase III trial in metastatic gastroesophageal adenocarcinoma with fluorouracil and leucovorin plus either oxaliplatin or cisplatin: A study of the arbeitsgemeinschaft internistische onkologie. J Clin Oncol 27: 2863-2873, 2009.

41. Song Y, Du Y, Zhou Q, Ma J, Yu J, Tao X and Zhang F: Association of GSTP1 Ile105Val polymorphism with risk of esophageal cancer: A meta-analysis of 21 case-control studies. Int J Clin Exp Med 7: 3215-3224, 2014.

42. Perazella MA: Onco-nephrology: Renal toxicities of chemotherapeutic agents. Clin J Am Soc Nephrol 7: 1713-1721, 2012 . 
43. Ulrich CM, Bigler J, Bostick R, Fosdick L and Potter JD: Thymidylate synthase promoter polymorphism, interaction with folate intake, and risk of colorectal adenomas. Cancer Res 62: 3361-3364, 2002.

44. Lecomte T, Ferraz JM, Zinzindohoué F, Loriot MA, Tregouet DA, Landi B, Berger A, Cugnenc PH, Jian R, Beaune P and Laurent-Puig P: Thymidylate synthase gene polymorphism predicts toxicity in colorectal cancer patients receiving 5-fluorouracilbased chemotherapy. Clin Cancer Res 10: 5880-5888, 2004.

45. Zhu S, Pabla N, Tang C, He L and Dong Z: DNA damage response in cisplatin-induced nephrotoxicity. Arch Toxicol 89: 2197-2205, 2015.
46. Bradbury PA, Kulke MH, Heist RS, Zhou W, Ma C, Xu W, Marshall AL, Zhai R, Hooshmand SM, Asomaning K, et al: Cisplatin pharmacogenetics, DNA repair polymorphisms, and esophageal cancer outcomes. Pharmacogenet Genomics 19: 613-625, 2009.

47. Yu HP, Wang XL, Sun X, Su YH, Wang YJ, Lu B, Shi LY, Xiong CL, Li YY, Li F and Xu SQ: Polymorphisms in the DNA repair gene XPD and susceptibility to esophageal squamous cell carcinoma. Cancer Genet Cytogenet 154: 10-15, 2004.

48. Li RZ and Sun J: Association between XPD gene polymorphisms and esophageal squamous cell carcinoma. Mol Med Rep 7: 674-678, 2013. 